\title{
Tool edge radius effect on cutting temperature in micro-end-milling process
}

\author{
Kai Yang • Ying-chun Liang • Kang-ning Zheng • \\ Qing-shun Bai $\cdot$ Wan-qun Chen
}

Received: 16 December 2009/Accepted: 15 June 2010 / Published online: 25 June 2010

(C) The Author(s) 2010. This article is published with open access at Springerlink.com

\begin{abstract}
The cutting temperature plays an important role in micro-scale cutting process due to the fact that the dimension of the micro-cutter is small and the value of micro-cutter wear is sensitive to temperature. In this paper, the temperature distribution of the micro-cutter in the micro-end-milling process has been investigated by numerical simulations and experimental approach. Micro-end-milling processes are modeled by the three-dimensional finite element method coupling thermal-mechanical effects. The microcutter cutting temperature distribution, the effect of various tool edge radii on cutting force, and the effective stress during micro-end-milling of aluminum alloy Al2024-T6 using a tungsten-carbide micro-cutter are investigated on. The simulation results show that with increase of tool edge radius the cutting force increases, while the effective stress and mean cutting temperature decreases slightly. In increasing the tool edge radius, the maximum effective stress and cutting temperature region of the micro-cutter occur from the rake
\end{abstract}

\footnotetext{
K. Yang $(\varangle) \cdot$ Y.-c. Liang $\cdot$ Q.-s. Bai $\cdot$ W.-q. Chen

School of Mechatronics Engineering,

Harbin Institute of Technology,

Harbin 150001, China

e-mail: yangkaihit@gmail.com

Y.-c. Liang

e-mail: ycliang@hit.edu.cn

Q.-s. Bai

e-mail: qshbai@hit.edu.cn

W.-q. Chen

e-mail: chwq1987@163.com

K.-n. Zheng

School of Management, Harbin Institute of Technology,

Harbin 150001, China

e-mail: zhengkangning@163.com
}

face to the corner on the tool edge and the flank face. The tool edge radius has been found to be the major factor affecting micro-cutter temperature distribution. The experimental verification of the simulation model is carried out on a micro-end-milling process of aluminum alloy 2024-T6 with a high-precision infrared camera. The influence of tool edge radius on cutting temperature distribution was verified in experiments.

Keywords Micro-cutter-Temperature distribution . Tool edge radius $\cdot$ FEM $\cdot$ Infrared imaging

\section{Introduction}

The development and manufacturing of highly accurate and miniaturized components with complex shape are becoming increasingly important in diverse fields, such as aviation aerospace, biomedicine, medical instruments, and communication systems [1]. The micro-end-milling technology has the advantage to remove materials mechanically using a miniature tool to fabricate real three-dimensional features with a variety of engineering materials.

Thermal field and cutting temperature in metal machining have been recognized to be the major factors affecting the tool wear, tool life, machine quality, part dimensional accuracy, and residual stresses. A fundamental understanding of thermal transfer mechanisms and temperature distribution is becoming essential. A lot of typical work has been done to investigate the cutting temperature in metal machining operations with finite element and experimental methods [2-4]. Kim KW, Lee WY, and Sin H researched the characteristics of temperature and stress in the micro-machining process by finite element method. They found that the effect of temperature on micromachining process cannot be ignored. Ignoring temperature 
effect, the flow stress is overestimated, which causes the cutting force to be calculated at twice that of the case of considering temperature effect. Therefore, considering the temperature effect is very important even for the micromachining process [5]. [6] proposed a finite difference method model to determine the three-dimensional temperature fields on the chip, tool, and workpiece during machining and validated the simulation results with infrared thermal measurements under various cutting conditions. Lazoglu I and Altintas Y developed a numerical model to predict tool and chip temperature fields in continuous machining and time-varying milling processes [7]. In [8] published by Sutter $\mathrm{G}$ and Ranc N, a ballistic device was developed to investigate chip temperature fields in a high-speed orthogonal cutting process. In order to measure the temperature on the flank face of a cutting tool, Ueda developed a two-color pyrometer for high-speed milling. The main result of this analysis is that the temperature distribution on the flank face of the tool is almost constant. In contrast, the temperatures at the tool corner and at the tool-work boundary are a little higher [9]. M'Saoubi R and Chandrasekaran $\mathrm{H}$ investigated the effects of tool micro-geometry and coating on tool temperature using dedicated infrared CCD sensors during an orthogonal turning process [10]. Arrazola P J, Arriola I, and Davies M A investigated micro-scale thermal fields in orthogonal cutting processes with an infrared microscope, which was used to analyze the effect of tool type, coatings, and machinability. The results indicate that, in certain critical regions of the thermal field, improved machinability correlates with significant reductions of temperature that exceed measurement uncertainties [11, 12]. Tool edge radius effect is the most significant characteristic of the micro-scale milling operation. Some efforts have been carried out to explain it [13-15]. Yuan Z J, Zhou M, and Dong $S$ investigated the influence of minimum chip thickness on the surface roughness in diamond cutting of aluminum alloys by experimental methods. It was found that the minimum chip thickness is approximately between $20 \%$ and $40 \%$ of the cutting edge radius [16]. [17] developed a finite element method to investigate the effects of various tool edge radiuses and tool tip breakage on the burr formation.

Cutting heat has been extensively investigated in conventional operations. However, there were a few researches regarding the size effect of machining conditions on temperature distribution during micro-end-milling. As the conventional milling process is scaled down to the micro-scale, the temperature distribution may show distinct differences from traditional machining due to size effects. The goal of this research work is to provide an understanding of the effect of cutting heat in microend-milling process with a series of numerical simulations and experiments.

\section{Finite element simulation model}

A commercial finite element analysis system Deform-3D ${ }^{\mathrm{TM}}$ v5.1 was used to solve the transient heat transfer problem and simulate the cutting temperature distribution of the micro-cutter. Figure 1 shows the geometry model of the dual-edge micro-cutter with various tool edge radii (sharp tool, $r_{\mathrm{n}}=3.2 \mu \mathrm{m}, r_{\mathrm{n}}=5.0 \mu \mathrm{m}, r_{\mathrm{n}}=7.0 \mu \mathrm{m}$ ). Table 1 lists the geometry parameters of the micro-cutter. The simulation length of the micro-cutter model is just $0.1 \mathrm{~mm}$ from the tool top end. Figure 1 shows a three-dimensional coupled thermal-mechanical finite element mesh model.

The workpiece material is aluminum alloy Al2024-T6, and the micro-cutter material is tungsten-carbide (WC-Co) with the diameter of $0.5 \mathrm{~mm}$.

The flow stress of the material is determined using the Johnson-Cook constitutive equation which is assumed to be a function of high strain, strain rate, and temperature. The workpiece material constitutive equation is defined in Eq. 1.

$\bar{\sigma}=\left[A+B(\bar{\varepsilon})^{n}\right]\left[1+C \ln \left(\frac{\dot{\bar{\varepsilon}}}{\dot{\bar{\varepsilon}}_{0}}\right)\right]\left[1-\left(\frac{T-T_{\text {room }}}{T_{\text {melt }}-T_{\text {room }}}\right)^{m}\right]$

In the above equation, $A$ is the yield strength of the material at room temperature and $\varepsilon$ represents the plastic equivalent strain. The strain rate $\varepsilon$ is normalized with a reference strain rate $\varepsilon_{0} . T$ is the workpiece temperature; $T_{\text {melt }}$ and $T_{\text {room }}$ are the material melting and room temperature, respectively.

In the 3D coupled thermo-mechanical analysis, the global distribution of the transient temperature is given by:

$\kappa\left(\frac{\partial^{2} T}{\partial x^{2}}+\frac{\partial^{2} T}{\partial y^{2}}+\frac{\partial^{2} T}{\partial z^{2}}\right)+\dot{Q}=\rho C \frac{\partial T}{\partial t}$

where $Q$ is the rate of specific volumetric heat flux and $t$ is the time.

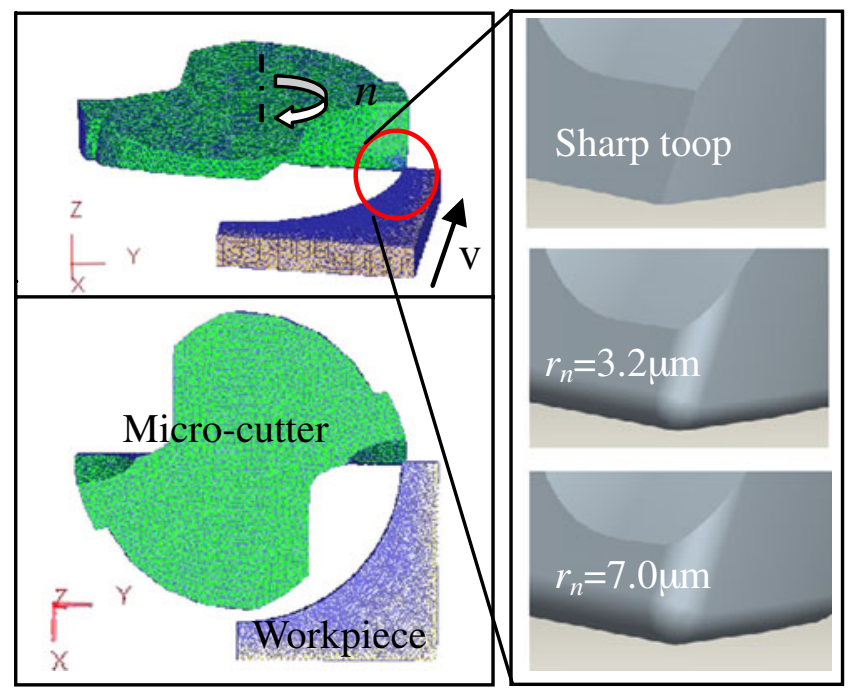

Fig. 1 Micro-end-milling FE model with various tool edge radii 
Table 1 Geometry parameters of micro-cutter

\begin{tabular}{llllll}
\hline Edge length $/ \mathrm{mm}$ & Edge diameter/mm & Edge radius $/ \mu \mathrm{m}$ & Rake angle ${ }^{\circ}$ & ${\text { Flank angle } /{ }^{\circ}}^{\text {Helix angle } /{ }^{\circ}}$ \\
\hline 1.0 & 0.5 & $0,3.2,5,7$ & 5 & 12 & 30 \\
\hline
\end{tabular}

The heat flux $q_{\mathrm{p}}$ results from the transformation of plastic work and shearing deformation and is defined by:

$q_{\mathrm{p}}=\frac{M f_{\mathrm{p}} W_{\mathrm{p}}}{\rho}$

where $M$ is the mechanical equivalent heat, $f_{\mathrm{p}}$ is the percentage of plastic work converted into heat (approximately 0.9 ), and $W_{\mathrm{p}}$ is the plastic work.

The heat flux $q_{\mathrm{c}}$, which is dissipated to the environment by convection from the micro-cutter or from the workpiece surfaces, is described by:

$q_{\mathrm{c}}=h_{\mathrm{c}}\left(T_{\mathrm{t}}-T_{\text {room }}\right)$

where $h_{\mathrm{c}}$ is the heat transfer coefficient of the workpiece material, $T_{\mathrm{t}}$ is the transient temperature of the material melting temperature, and $T_{\text {room }}$ is the room temperature.

Frictional effects are very complicated and cannot be ignored in micro-end-milling. In this study, the Coulomb friction law is used to define the friction at the tool-chipworkpiece contacts. This model can be represented by:

$\tau_{\mathrm{f}}=\mu \sigma_{\mathrm{n}}$ when $\tau_{\mathrm{f}}<k$

$\tau_{\mathrm{f}}=\kappa$ when $\tau_{\mathrm{f}} \geq \kappa$

where $\tau_{\mathrm{f}}$ is the frictional stress, $\sigma_{\mathrm{n}}$ is the normal stress, $\mu$ is the coefficient of friction, and $k$ is the shear stress of the chip material. However, it is very difficult to determine the coefficient of friction because the frictional conditions in the micro-end-milling process are different from those of the conventional milling process. The hardness of the chip was much higher than that of the workpiece in the micro-scale machining process because of the plastic deformation in the chip. This hardness variation may cause changes in the coefficient of friction. Based on experimental research results and related references [5, 18], a constant friction factor of 0.7 is used in the finite element (FE) model. In "Section 4" of this paper, the average cutting temperature of simulation results has agreed with that of the experiments which shows that the value of friction factor set as 0.7 is acceptable.

\section{Simulation results and discussion}

In this section, the effect of tool edge radii on the simulated cutting force, effective stress, and cutting temperature are investigated during the micro-end-milling process. The configurations of the simulation cutting parameters are: spindle speed $(n)$ of $140,000 \mathrm{rad} / \mathrm{min}$, cutting width $\left(a_{\mathrm{w}}\right)$ of $0.25 \mathrm{~mm}$, cutting depth $\left(a_{\mathrm{p}}\right)$ of $10 \mu \mathrm{m}$, feed per tooth $f_{\mathrm{z}}$ of $0.1 \mu \mathrm{m}$, and tool edge radius of sharp tool, $r_{\mathrm{n}}=3.2 \mu \mathrm{m}, r_{\mathrm{n}}=$ $5.0 \mu \mathrm{m}$, and $r_{\mathrm{n}}=7.0 \mu \mathrm{m}$, respectively.

\subsection{Cutting force}

In micro-scale milling process, the size effect is typically characterized by a non-linear increase in the specific cutting force as the minimum chip thickness is decreased. Figure 2 shows a schematic diagram of the tool tip trajectory of the micro-cutter in the micro-end-milling. The exact trochoid trajectory was dynamically simulated (from A to B). Figure 3 shows variations of the simulated cutting force with various tool edge radii, 3.2, 5.0, and $7.0 \mu \mathrm{m}$, respectively. It can be seen that the cutting forces increase rapidly as the tool advances into the workpiece. When the micro-cutter cutting edge radii are between 3 and $5 \mu \mathrm{m}$, the cutting force did not change significantly. However, as the micro-cutter cutting edge radius is equal to $7 \mu \mathrm{m}$, the cutting force changed significantly. [16] showed that the minimum chip thickness is approximately between $20 \%$ and $40 \%$ of the cutting edge radius. This simulation also showed that, when the tool edge radius is set as $7 \mu \mathrm{m}$, feed per tooth $f_{\mathrm{z}}$ of $0.1 \mu \mathrm{m}$, the ratio of feed to tool edge radius $\left(f_{\mathrm{t}} / r_{\mathrm{n}}\right)$ is less than the critical chip thickness. Thus, under this cutting condition, the cutting force increased significantly.

\subsection{Effective stress distribution of micro-cutter}

Figure 4 shows the contours of the effective stress of chip, workpiece, and micro-cutter with various cutting edge radii

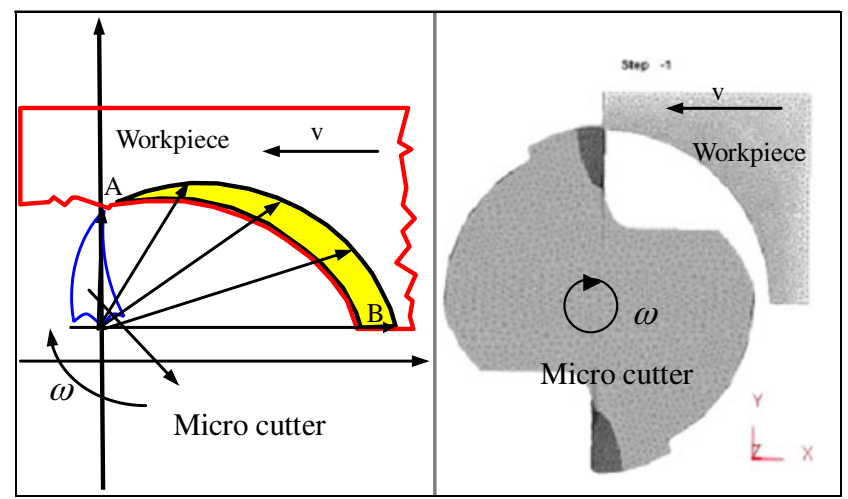

Fig. 2 Schematic diagram of micro-cutter path 


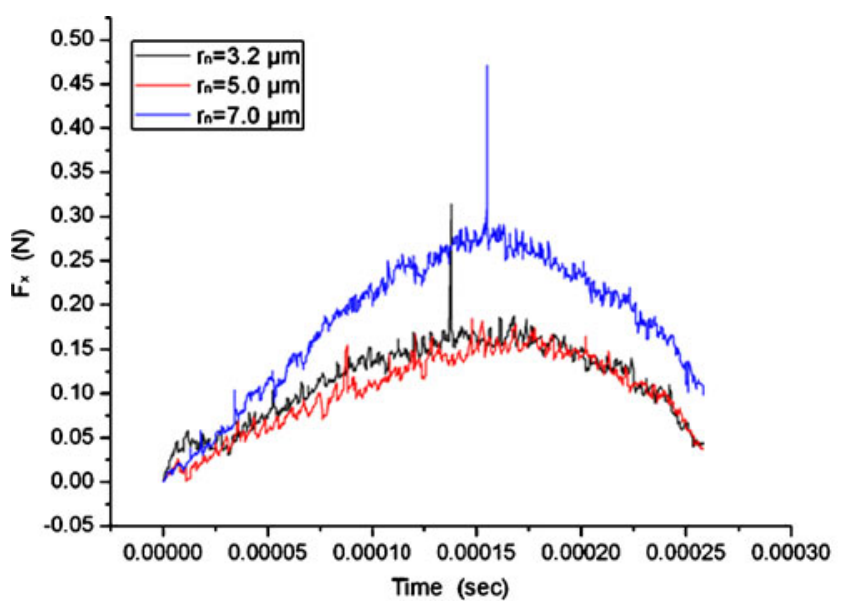

a) Feed force $F_{x}$

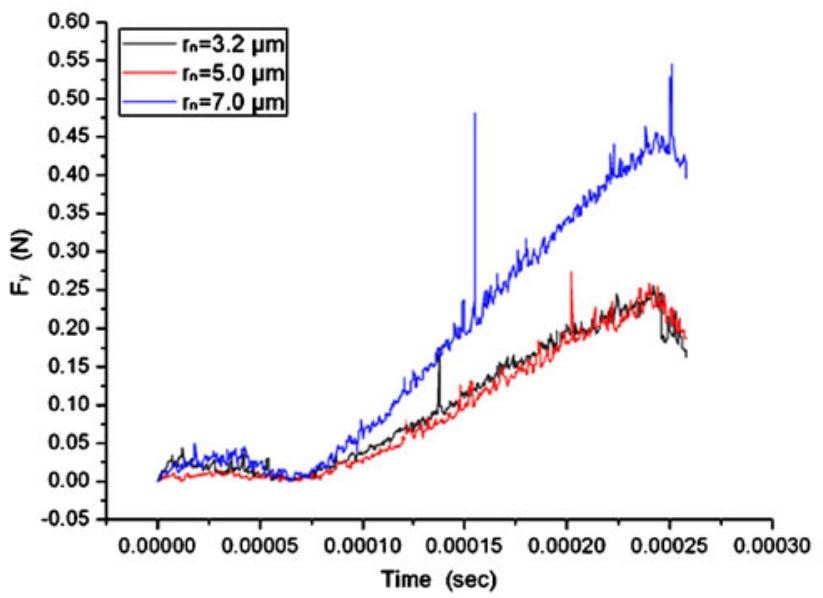

b) Normal force $F_{y}$

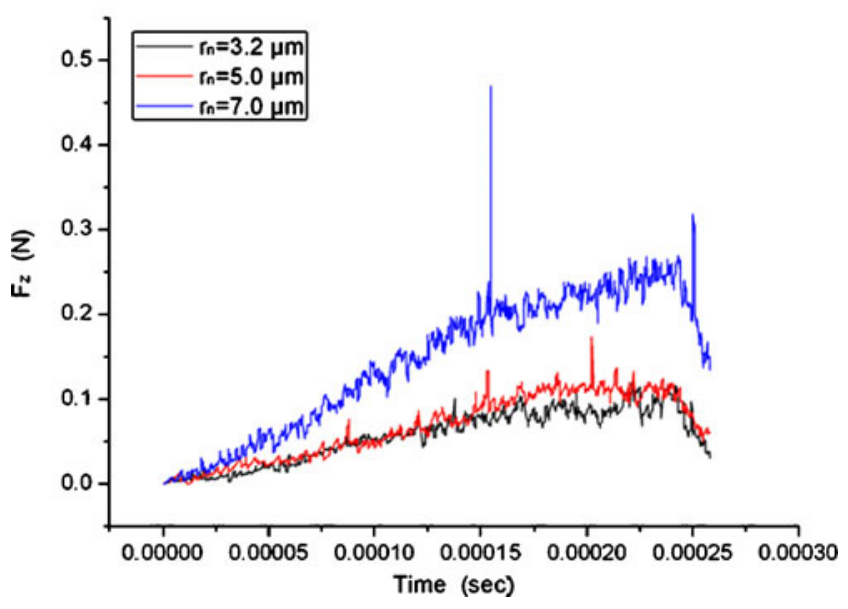

c) Axis force $F_{z}$

Fig. 3 a-c Effect of tool edge radius on three different cutting forces

of a sharp tool, 3.2, 5.0, and $7.0 \mu \mathrm{m}$, respectively. It can be seen that the maximum effective stress only occurs in very small regions of the micro-cutter and workpiece. As shown above, Fig. 4a shows a state generated by a continuing cutting chips, Fig. $4 b, c$ are states that occurred by interrupted chips, and
Fig. 4d shows a state without any cutting chips. The maximum effective stress of the micro-cutter is obviously higher than that of the workpiece and the chip. With an increase of tool edge radius, the maximum effective stress regions are located at the rake face of the micro-cutter (Fig. 4a), helix cutting edge corners (Fig. 4b), the end cutting edge (in Fig. 4c), and the flank face of the micro-cutter (Fig. 4d), respectively. The maximal effective stress is 647 , 599,560 , and $460 \mathrm{MPa}$, respectively. With an increase of tool edge radius, the position of a high stress region occurs from the rake face of the micro-cutter to the flank face. Meanwhile, the maximum stress of the micro-cutter decreases obviously, but it is still much higher than that of the conventional milling process. The maximum stress distribution micro-cutter and workpiece contact zone is the most seriously frictional region, and the heat generated by friction will be directly imported to the micro-cutter. This will directly affect the temperature distribution of the micro-cutter on the contact region.

\subsection{Temperature distribution of the micro-cutter}

The cutting temperature plays an important role in every metal cutting process due to its effects on the tool wear and on the quality of the finished surface. Figure 5 shows the temperature distributions of the micro-cutter which were calculated for four different tool edge radii. The transient temperature distribution was dynamically simulated during the micro-end-milling process. The simulation results show that, with an increase of the tool edge radius, the maximal cutting temperatures of the micro-cutter are $57.5^{\circ} \mathrm{C}, 51.5^{\circ} \mathrm{C}$, $45.4^{\circ} \mathrm{C}$, and $40.4^{\circ} \mathrm{C}$. The cutting temperatures of the microcutter are very low compared to conventional milling conditions. With a sharp tool (Fig. 5a), the maximum temperature occurs in the rake face of the micro-cutter with a certain distance from the end cutting edge due to the cutting chips flowing to the rake face and taking away most of the cutting heat. When the tool edge radius is $3.2 \mu \mathrm{m}$ (Fig. 5b) or $5.0 \mu \mathrm{m}$ (Fig. 5c), the maximum cutting temperature region does not occur in the rake face of the micro-cutter but in the helix cutting edge (Fig. 5b) and end cutting edge (Fig. 5c). In this cutting simulation condition, the cutting chips occurred intermittently and take away part of the cutting heat. When the tool edge radius is $7.0 \mu \mathrm{m}$, there was no chip formation (Fig. 5c), because the rate of feed per tooth to tool edge radius $\left(f_{\mathrm{t}} / r_{\mathrm{n}}\right)$ is less than the critical value of the minimum chip thickness. The cutting heat is not dissipated by the chip but by the finished surface and the flank face of the micro-cutter. This result demonstrates the generated cutting heat between the friction of the micro-cutter and the workpiece and that the plowing effect plays a dominant role on micro-end-milling processes with the $7.0-\mu \mathrm{m}$ radius which is the major reason for the heat generation. 


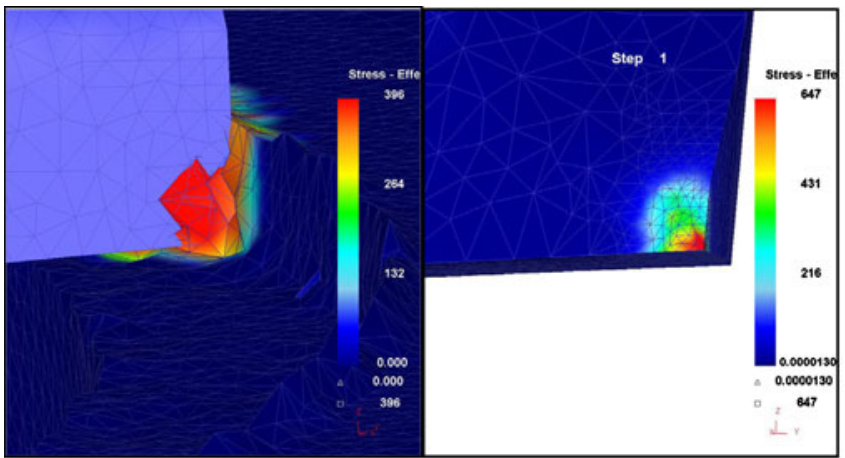

a) Sharp tool

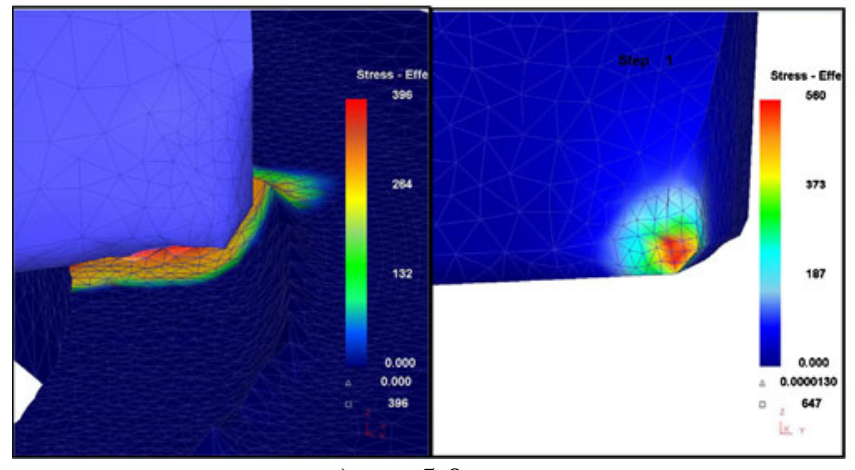

c) $r_{n}=5.0 \mu \mathrm{m}$

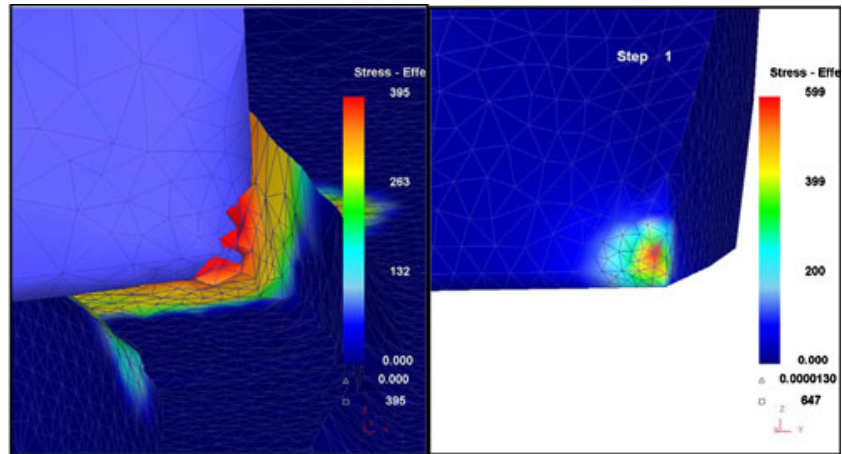

b) $r_{n}=3.2 \mu \mathrm{m}$

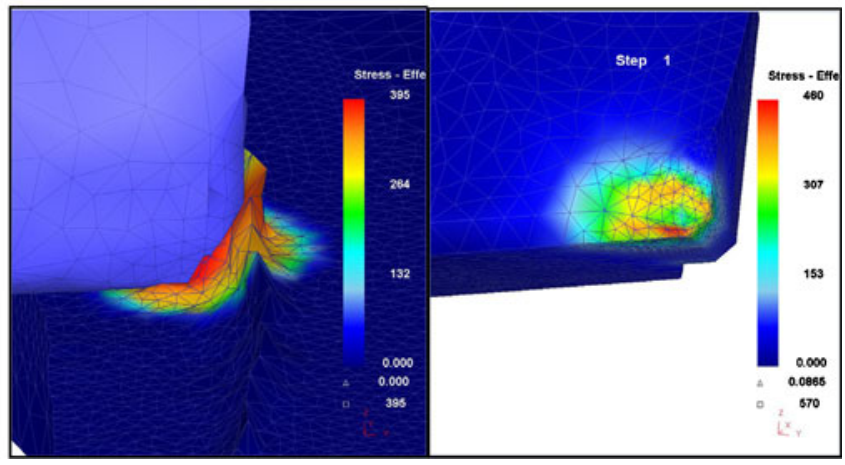

d) $r_{n}=7.0 \mu \mathrm{m}$

Fig. 4 a-d The effect of tool edge radius on effective stress distribution

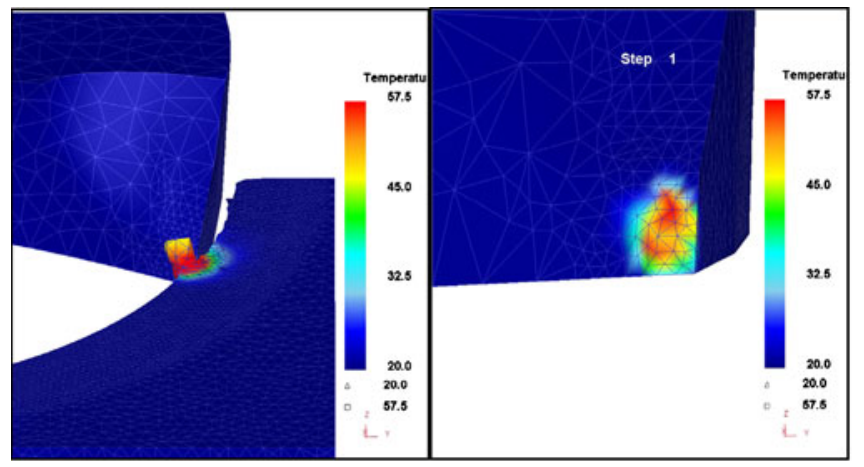

a) Sharp tool

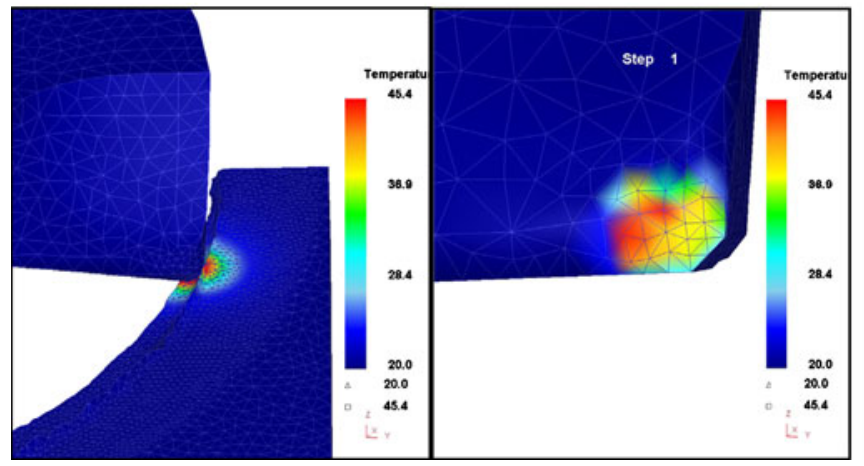

c) $r_{n}=5.0 \mu \mathrm{m}$

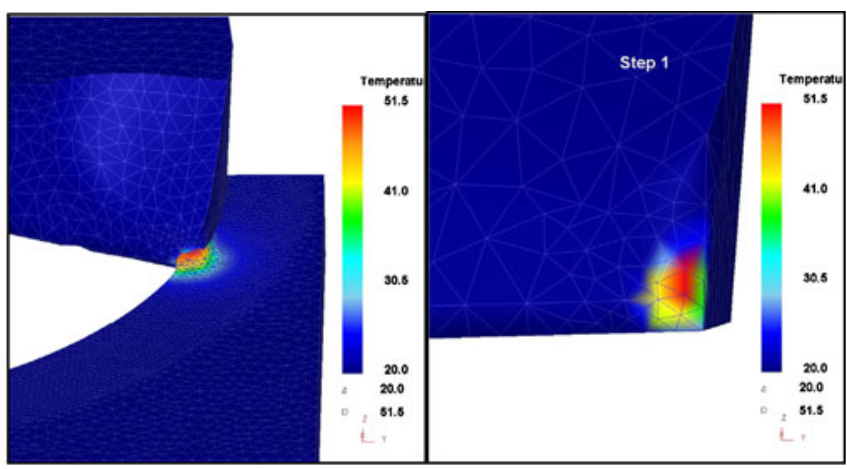

b) $r_{n}=3.2 \mu \mathrm{m}$

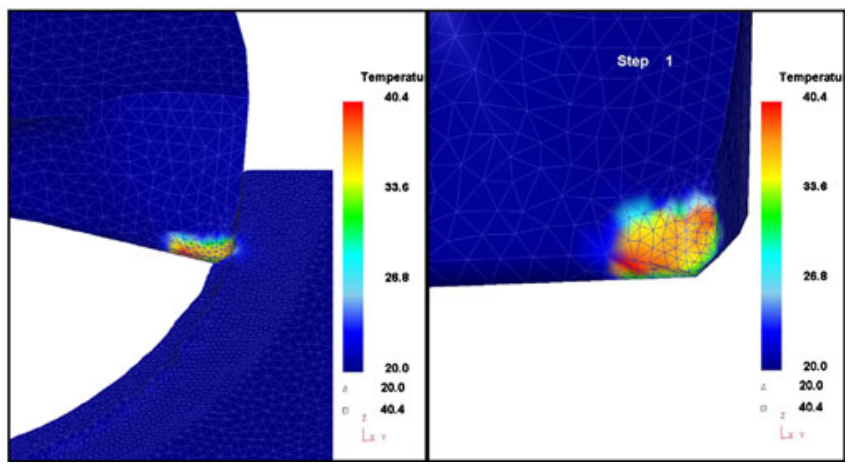

d) $r_{n}=7.0 \mu \mathrm{m}$

Fig. 5 a-d Temperature distribution of micro-cutter 


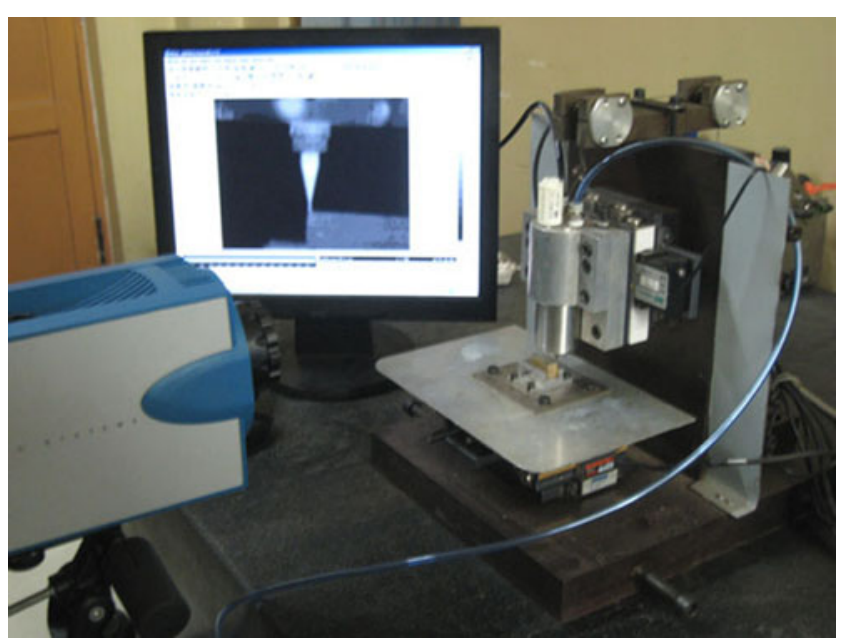

Fig. 6 Micro-milling machine and infrared thermal imaging system

\section{Model validation}

\subsection{Experimental setup}

A larger number of micro-end-milling aluminum alloy A12024-T6 operations were performed on a developed three-axis precision vertical CNC micro-milling machine (as shown in Fig. 6). An air motor spindle with rotating speeds from 100,000 to $160,000 \mathrm{rad} / \mathrm{min}$ (rpm) was used in the experiments. The spindle speed was controlled by changing the air pressure. The feed system of this machine consists of three precision linear stages and each stage of the workpiece is driven by the piezoelectric actuators. PMAC was used to control the system.

In order to validate the prediction of cutting temperature by the present FE model, an infrared thermal imaging system was used to measure the cutting temperature signals,

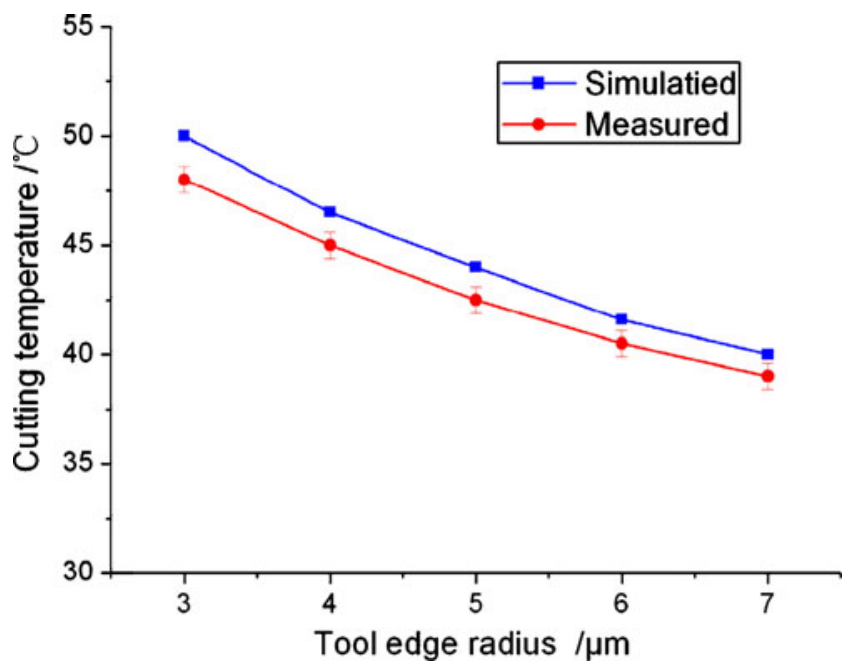

Fig. 8 Comparison of cutting temperature between experiments and predictions

which utilizes a $320 \times 240$ array and the temperature resolving power is about $\pm 0.02^{\circ} \mathrm{C}$. The two commercial tungsten-carbide (WC) micro-cutters with different tool edge radii are used in this experiment. The geometry parameters of the micro-cutter are the same as those of the simulation model. Aluminum alloy A12024-T6 was used as a workpiece material.

\subsection{Experiment results and discussion}

In order to validate the predictive simulation results of the cutting temperature of the micro-cutter by FE model, the configurations of cutting parameters are the same as those in the simulation ("Section 3.2"): spindle speed $(n)$ of $140,000 \mathrm{rad} / \mathrm{min}$, cutting width $\left(a_{\mathrm{w}}\right)$ of $0.25 \mathrm{~mm}$, cutting depth $\left(a_{\mathrm{p}}\right)$ of $10 \mu \mathrm{m}$, and feed per tooth $f_{\mathrm{z}}$ of $10 \mu \mathrm{m}$.

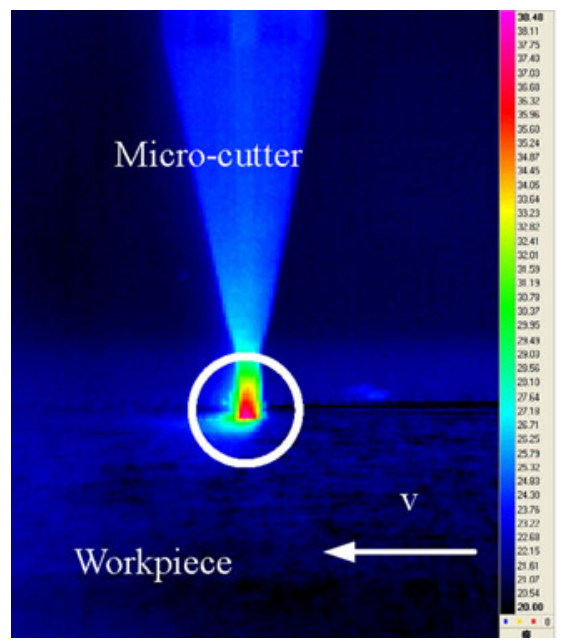

a) Cutting temperature analyzing zone

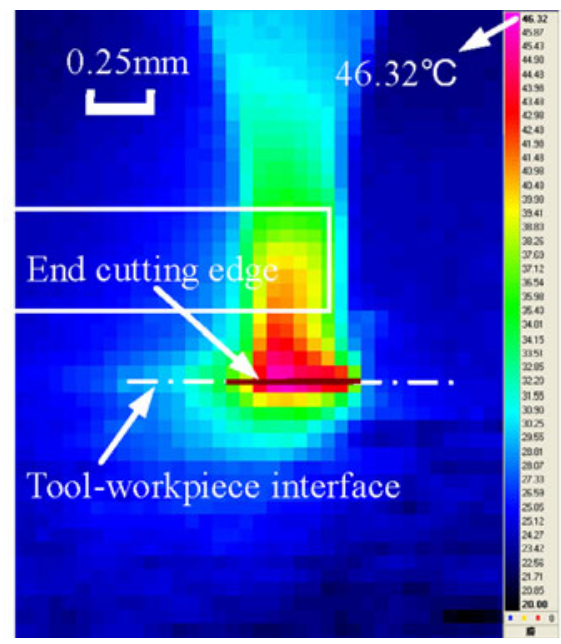

b) The enlarged image $\left(r_{n}=3.2 \mu \mathrm{m}\right)$

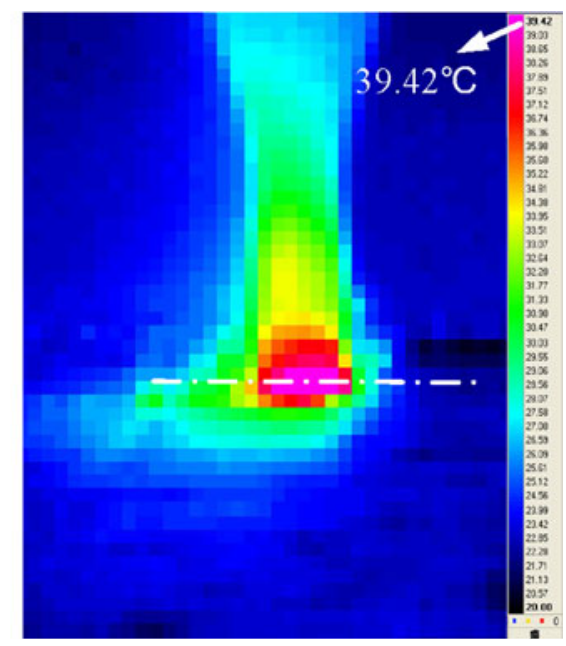

c) The enlarged image $\left(r_{n}=5.0 \mu m\right)$

Fig. 7 a-c The effect of tool edge radii on cutting temperature distribution 
Figure $7 \mathrm{a}$ shows the results of measured cutting temperature captured by the IR system in micro-end-milling process of A12024-T6. The temperature distribution of the microcutter will be investigated with the partially enlarged image (Fig. $7 b, c)$. It was found that the high temperature occurs on the contact zone between the tool and the workpiece, and the peak temperature of the micro-cutter was found on the end cutting edge. The thermal effect only focuses on a small region near the contact area. The occurring temperatures are very low compared to conventional milling conditions due to small loads and rapid heat diffusion of aluminum alloy A12024-T6. At an edge radius of $5.0 \mu \mathrm{m}$ (Fig. 7c), the peak temperature is higher than that at an edge radius of $3.2 \mu \mathrm{m}$ (Fig. 7b). The variety trend of the measured temperature is similar to the simulation results.

Figure 8 shows comparison of cutting temperature between experiments and predictions. It can be seen from Fig. 8 that, with an increase of varied tool edge radii, the overall cutting temperatures of measured results and simulated results are decreasing. The measured results of cutting temperature are below the simulated results. This simulation, without consideration of heat dissipation of the micro-cutter, predicts that cutting temperatures will possibly increase. The tool edge radius of the micro-cutter is increased during the processes of micro-end-milling which will cause the decrease of cutting temperature in the experiment. This may be the reason for causing errors between simulated results and experimental measured results. Although errors exist, the results of comparison between experiments and predictions of Fig. 8 are acceptable.

\section{Conclusions}

Based on the results and discussions presented in this paper, it can be concluded that:

(1) A new coupled thermo-mechanical finite element model was developed for micro-end-milling of aluminum alloy A12024-T6. From the simulation results, it could be seen that the occurring temperatures are very low compared to conventional milling conditions. The thermal effect only focuses on a small region near the contact area.

(2) The simulation results show that, with an increase of tool edge radius, the cutting force increases, while the effective stress and mean cutting temperature of the micro-cutter decreases slightly.

(3) When the ratio of undeformed chip thickness to tool edge radius is less than about $40 \%$, increasing tool edge radius, the maximum effective stress, and the cutting temperature zone of micro-cutter occur from the rake face to the corner on the tool edge and the flank face, with a distinct obvious size effect.
(4) The experimental measured results are below the simulated results and, with an increase of varied tool edge radii, the trend of cutting temperatures of measured results and simulated results are congruous.

Acknowledgements The authors acknowledge the National Outstanding Youth Science Foundation of China (No.50925521) and the National Natural Science Foundation of China (No. 50705023).

Open Access This article is distributed under the terms of the Creative Commons Attribution Noncommercial License which permits any noncommercial use, distribution, and reproduction in any medium, provided the original author(s) and source are credited.

\section{References}

1. Chae J, Park SS, Freiheit T (2006) Investigation of micro-cutting operations. Int J Mach Tools Manuf 46:313-332

2. Komanduri R, Hou ZB (2001) A review of the experimental techniques for the measurement of heat and temperatures generated in some manufacturing processes and tribology. Tribol Int 34:653-682

3. Richardson DJ, Keavey MA, Dailami F (2006) Modelling of cutting induced workpiece temperatures for dry milling. Int J Mach Tools Manuf 46:1139-1145

4. Dinc C, Lazoglu I, Serpenguzel A (2008) Analysis of thermal fields in orthogonal machining with infrared imaging. J Mater Process Technol 198:147-154

5. Kim KW, Lee WY, Sin H (1999) A finite element analysis for the characteristics of temperature and stress in micro-machining considering the size effect. Int J Mach Tools Manuf 39:15071524

6. Ulutan D, Lazoglu I, Dinc C (2009) Three-dimensional temperature predictions in machining processes using finite difference method. J Mater Process Technol 209:1111-1121

7. Lazoglu I, Altintas Y (2002) Prediction of tool and chip temperature in continuous and interrupted machining. Int J Mach Tools Manuf 42:1011-1022

8. Sutter G, Ranc N (2007) Temperature fields in a chip during high speed orthogonal cutting - an experimental investigation. Int $\mathrm{J}$ Mach Tools Manuf 47:1507-1517

9. Ueda T, Hosokawa A, Oda K, Yamada K (2001) Temperature on flank face of cutting tool in high speed milling. Ann CIRP 50:3740

10. M'Saoubi R, Chandrasekaran H (2004) Investigation of the effects of tool micro-geometry and coating on tool temperature during orthogonal turning of quenched and tempered steel. Int J Mach Tools Manuf 44:213-224

11. Arrazola PJ, Arriola I, Davies MA (2008) The effect of machinability on thermal fields in orthogonal cutting of AISI 4140 steel. CIRP Ann Manuf Technol 57:65-68

12. Arrazola PJ, Arriola I, Davies MA (2009) Analysis of the influence of tool type, coatings, and machinability on the thermal fields in orthogonal machining of AISI 4140 steels. CIRP Ann Manuf Technol 58:85-88

13. Vogler MP, Devor RE, Kapoor SG (2003) Microstructure-level force prediction model for micro-milling of multi-phase materials. ASME J Manuf Sci Eng 125:202-209

14. Liu X, DeVor RE, Kapoor SG (2006) An analytical model for the prediction of minimum chip thickness in micromachining. $\mathrm{J}$ Manuf Sci Eng 128:474-481 
15. Lai XM, Li HT, Li CF (2008) Modelling and analysis of micro scale milling considering size effect, micro cutter edge radius and minimum chip thickness. Int J Mach Tools Manuf 48:1-14

16. Yuan ZJ, Zhou M, Dong S (1996) Effect of diamond tool sharpness on minimum cutting thickness and cutting surface integrity in ultra precision machining. J Mater Process Technol 62:327-330
17. Liang YC, Yang K, Bai QS, Chen JX, Wang B (2009) Modeling and experimental analysis of microburr formation considering tool edge radius and tool-tip breakage in microend milling. J Vac Sci Technol B 1531-1535

18. Aurich JC, Bil H (2006) 3D finite element modelling of segmented chip formation. Ann CIRP 55:47-50 